\title{
The relationship between nurse-nurse collaboration and patient safety: A cross-sectional study
}

\author{
Yeliz Karaçar $^{1}$, Kerime Bademli ${ }^{1}$, Mustafa Levent Ozgonul ${ }^{1}$, and Nurcan Kırca ${ }^{1}$ \\ ${ }^{1}$ Akdeniz University
}

September 24, 2021

\begin{abstract}
ABSTRACT Objectives: To investigate the relationship between nurse-nurse collaboration and patient safety attitudes in inpatient care. Methods: This was a cross-sectional study. In the study, the sample universe was determined by the known sampling method and a total of 160 nurses working in inpatient clinics of a public hospital between January-March 28,2020 were included in the study. The data were collected using the "Personal Information Form", "Nurse-Nurse Collaboration Scale" and "Patient Safety Attitude Questionnaire". Descriptive statistics, t-test, ANOVA, correlation, and linear regression analysis were used to analyze the data. Results: The mean scores of the nurse-nurse collaboration $(78.55 \pm 8.86)$ and patient safety attitude $(162.68 \pm 20.59)$ found to high level. It was revealed that the nurses' higher level of collaboration with increasing work experience. Patient safety attitudes, job satisfaction, safety climate and perceptions of management of the manager nurses were higher than those of clinical nurses. Nurse-nurse collaboration has a statistically significant effect on patient safety attitude of nurses. The results show that $\% 24$ of the change in patient safety attitude in nurses could be explained by nurse-nurse collaboration. Conclusions: It was determined that, the nurse-nurse collaboration was significantly associated with patient safety attitudes. Our findings provided new evidence that it could be argued that, as the level from nurse-nurse collaboration increase, the level on patient safety attitude of nurses will increase. This study proposes that improving nurse-nurse collaboration should be regarded as a significant strategy that would increase patient safety. Key Words: collaboration, hospital, inpatient, patient safety, nursing
\end{abstract}

\section{Hosted file}

Manuscript 17 . 08. 2021.docx available at https://authorea.com/users/435796/articles/538570the-relationship-between-nurse-nurse-collaboration-and-patient-safety-a-cross-sectionalstudy

\section{Hosted file}

Tables 17.08.2021.docx available at https://authorea.com/users/435796/articles/538570-therelationship-between-nurse-nurse-collaboration-and-patient-safety-a-cross-sectionalstudy 